\title{
Vagal Tone as a Putative Mechanism for Pragmatic Competence: An Investigation of Carriers of the FMR1 Premutation
}

\author{
Jessica Klusek $^{1}\left[\right.$ D Amanda J. Fairchild ${ }^{2}$ Jane E. Roberts ${ }^{2}$
}

Published online: 10 August 2018

๑) Springer Science+Business Media, LLC, part of Springer Nature 2018

\begin{abstract}
Pragmatic language skills exist across a continuum in typical and clinical populations, and are impaired in many neurodevelopmental disorders, most notably autism. The mechanisms underlying pragmatic impairment are poorly understood, although theory suggests dampened vagal tone plays a role. This study investigated the FMR1 premutation as a genetic model that may lend insight into the relationship between vagal function and pragmatic ability. Participants included 38 women with the FMR 1 premutation and 23 controls. Vagal tone accounted for significant variance in pragmatics across both groups and statistically mediated the effect of $F M R l$ premutation status on pragmatic ability. Results support vagal tone as a biophysiological correlate of pragmatic ability, which informs potential mechanistic underpinnings and could have implications for targeted treatment.
\end{abstract}

Keywords Fragile X carrier $\cdot \mathrm{HRV} \cdot \mathrm{RSA} \cdot$ Social communication $\cdot$ Social (Pragmatic) Communication Disorder

The social use of language, or pragmatic language, is a fundamental component of communicative competence (Prutting 1982). Pragmatic language skills encompass knowing what to say, and how and when to say it; this knowledge is implicitly required for successful communication, such as holding a back-and-forth conversation, telling a cohesive story, and clarifying misunderstandings. Deficits in pragmatic language can have a substantial impact on social functioning and are linked with loneliness, poor social-emotional adjustment, difficulty managing social relationships, social isolation, externalizing problems, antisocial behavior, and risk for psychological disorders such as social phobia (Coplan and Weeks 2009; Geurts et al. 2004; Jobe and White 2007; Ketelaars et al. 2010; Laws et al. 2012; Whitehouse et al. 2009). Despite evidence that the majority of individuals with pragmatic difficulties in childhood continue to face persistent problems into adulthood (Conti-Ramsden et al.

Jessica Klusek

klusek@mailbox.sc.edu

1 Department of Communication Sciences and Disorders, University of South Carolina, Keenan Building, 1229 Marion Street, Columbia, SC 29201, USA

2 Department of Psychology, Barnwell College, University of South Carolina, 1512 Pendleton Street, Columbia, SC 29208, USA
2001; Whitehouse et al. 2009), there is a scarcity of research on pragmatic competence in adults.

Many neurodevelopmental disorders, most notably autism spectrum disorder (ASD), are characterized by pragmatic deficits. Impairment in pragmatic aspects of communication is a feature that is universally observed across all individuals with ASD (Landa 2000). Indeed, the DSM-5 diagnostic criteria for ASD relies heavily on the presence of features that fall within the domain of pragmatic competence, such as failure to engage in back-and-forth conversation, poor integration of verbal and nonverbal communication, reduced initiation and sharing of interests, lack of gestures or facial expressions, stereotyped or repetitive speech, topic preoccupations, and abnormal eye contact (American Psychiatric Association 2013). Pragmatic deficits are also central to broader autism phenotypes observed in unaffected relatives of individuals with ASD, suggesting that pragmatic impairment is a core, biologically mediated component of ASD that is linked to underlying genetic susceptibility (Losh et al. 2008; Piven et al. 1997).

Pragmatic impairment in individuals who do not meet diagnostic criteria for ASD has also been frequently described in the literature, accompanied by much debate as to whether these deficits represent a distinct disorder or a milder form of ASD (e.g., Bishop and Norbury 2002; Brook and Bowler 1992; Reisinger et al. 2011). Recently, 
in recognition that pragmatic impairment can occur independently of ASD, Social (Pragmatic) Communication Disorder (SCD) was added as a new diagnostic category in the DSM-5 (American Psychiatric Association 2013). The introduction of SCD as a distinct disorder highlights that pragmatic deficits exist across a continuum in typical and clinical populations and provides a common framework from which to refine the conceptualization of pragmatic deficits occurring within and without of the context of ASD (Swineford et al. 2014). Understanding the presentation of pragmatic difficulties observed across typical and at-risk groups is important because it contributes to open questions in the field regarding the continuum of ASD-related features within the general population, and the mechanistic specificity of such features. The present study investigated biophysiological correlates of pragmatic competence occurring across neurotypical women and women who are at genetic risk for pragmatic language deficits due to carrying a genetic abnormality on the $F M R l$ gene.

\section{The Role of the Vagal Nerve in Pragmatic Competence}

According to Polyvagal Theory (Porges 2001, 2007), individual differences in social engagement skills can be accounted for by autonomic regulation via the vagal nerve. The vagus provides parasympathetic input that calms the heart, stifling sympathetic "fight or flight" impulses and allowing the body to establish a controlled physiological state that facilitates social engagement. Polyvagal Theory posits that the vagal nerve evolved in mammals to include myelinated fibers that allow parasympathetic signals to travel to the heart more efficiently, thereby promoting adaptive social behavior. In support of Polyvagal Theory, a wealth of evidence shows that high vagal tone is linked with enhanced social functioning in both children and adults (e.g., Calkins and Keane 2004; Demaree et al. 2004; Kok and Fredrickson 2010; Quintana et al. 2012). Applying Polyvagal Theory specifically to the study of pragmatic behavior, high vagal tone is associated with better concurrent pragmatic skills in children with ASD (Klusek et al. 2013) as well as at a oneyear follow-up (Watson et al. 2010). Knowledge of vagalpragmatic associations is limited to these two reports, and it remains unclear whether these relationships generalize to other clinical groups. Importantly, Polyvagal Theory provides a biophysiological explanation for pragmatic competence that can be applied across the continuum of typical and atypical development, which is consistent with recent scientific initiatives favoring dimensional, transdiagnostic approaches to understanding the biological bases of behavior (e.g., the Research Domain Criteria (RDoC); Insel 2014). In this study we investigated the FMRI premutation—a genetic abnormality associated with pragmatics deficits and dampened vagal tone-as a model for understanding the link between vagal function and pragmatic ability.

\section{The FMR1 Premutation}

The FMRI premutation affects 1 in 151 women and occurs when the trinucleotide (CGG) sequence on the Fragile $X$ Mental Retardation-1 (FMRI) gene expands to 55-200 repeats (Maddalena et al. 2001; Seltzer et al. 2012). This genetic abnormality is associated with excess production of FMRI messenger RNA (mRNA), which is thought to disrupt numerous cellular pathways, causing neuronal damage and death (Hagerman and Hagerman 2013). It was once mistakenly believed that carriers of the FMRI premutation showed no associated clinical effects besides the risk of passing the mutated gene to their children, which may result in fragile $\mathrm{X}$ syndrome. However, it is now evident that the FMRl premutation is associated with a range of physical, cognitive, and affective symptoms and disorders that impact health and quality of life (see Wheeler et al. 2017 for review). Notably, the penetrance of associated clinical effects is incomplete and the lack of identified biomarkers limits identification, prevention, and treatment efforts for this heterogeneous group.

A variety of social difficulties have been documented as part of the FMRl premutation phenotype, such as atypical use of eye gaze, elevated broad autism phenotype traits, and ASD occurring in about $5 \%$ of females with the premutation (Clifford et al. 2007; Klusek et al. 2017b, c; Losh et al. 2012; Schneider et al. 2016). Social deficits in this group extend to the domain of pragmatics. During conversational interaction with an examiner, women with the $F M R l$ premutation exhibit higher rates of pragmatic violations relative to control women, such as topic perseveration, interrupting, and over-talkativeness (Losh et al. 2012). Pragmatic violations in women with the FMRI premutation are associated with poorer language outcomes in their children with fragile $X$ syndrome, demonstrating the clinical significance of these features for both the individual and their family (Klusek et al. 2016). Pragmatic deficits are also seen in individuals with the full mutation on FMRI (i.e., fragile $\mathrm{X}$ syndrome), with some evidence that pragmatic deficits are tied to variation at the FMR1 locus (Klusek et al. 2014; Losh et al. 2012). Thus, pragmatic impairment represents a central phenotype associated with $F M R 1$ gene dysfunction.

FMRI-associated conditions provide a unique genetic context from which to study the clinical impact of vagal dysregulation. Dampened vagal tone is a well-documented, hallmark feature of fragile $\mathrm{X}$ syndrome that emerges early in the developmental course and is believed to reflect a biological signature of FMRI gene dysfunction (see Klusek et al. 


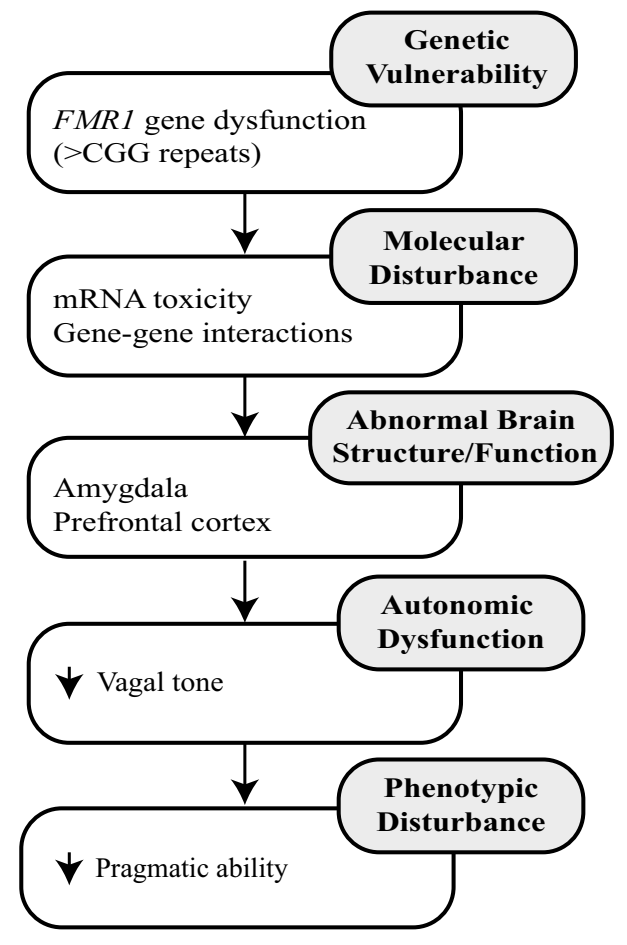

Fig. 1 Conceptual framework of atypical vagal function in the FMRI premutation. Framework based on the conceptual work of Roberts et al. (2011)

2015, for review; Roberts et al. 2012). Recent evidence suggests that dampened vagal tone also extends to the FMRI premutation, and is associated with $F M R I$ molecular genetic indices. Klusek et al. (2017a) detected lower baseline vagal tone in women with the FMR1 premutation compared to neurotypical control women, after accounting for confounds such as age, stress, and medication use. Interestingly, a significant, moderate association was detected between higher vagal tone and higher FMRl mRNA expression, which was unexpected given that excess FMR1 mRNA production is believed to be toxic to the neural system (Hagerman and Hagerman 2013). Thus, some questions remain regarding the specific mechanisms by which FMRI is linked to vagal function; however, this body of research, overall, suggests that vagal tone may represent an etiologically meaningful marker in FMRI-associated conditions. Combining this evidence with Polyvagal Theory, we hypothesized that vagal tone may mediate the relationship between FMRI gene dysfunction and clinical outcomes. Figure 1 presents a conceptual framework describing the process by which vagal dysregulation is thought to relate to pragmatic language difficulties, using the FMRI premutation as a model. In this framework, altered FMRI gene function leads to disturbance in cortical structures and pathways, particularly in the areas of the amygdala and prefrontal cortex (Brown and Stanfield 2015; Hessl et al. 2007, 2011). These brain regions are also thought to be important for autonomic regulation (see Thayer et al. 2012). Disturbance in these higher brain circuits is believed to result in impaired ability to process and respond to input regarding the body's physiological state via the vagal nerve (the vagus provides bi-directional communication between the brain and heart via projections to the brainstem and sinoatrial node; Porges 2003). Thus, capability for quick, flexible physiological adjustments via the vagal nerve is reduced, which, consistent with Polyvagal Theory, negatively impacts social engagement, including pragmatic competence. In line with this conceptual framework, the present study employed statistical mediation analysis to test the hypothesis that vagal tone mediates the impact of FMRI premutation genetic status on pragmatic language ability. By leveraging the FMRI premutation as an etiological model for pragmatic deficits, this study aims to yield novel information on the physiological correlates of social communication behavior that may have relevance to both individuals with and without FMR1 mutations.

\section{Methods}

\section{Participants}

Participants included 38 women with the FMRI premutation and 23 neurotypical control women. Participants were enrolled in a larger study focused on women with the FMRI premutation, which has been previously described (Klusek et al. 2017a). All participants were native speakers of American English and biological mothers of a child 4 years or older. The FMRl premutation was confirmed via genetic testing $(87 \%)$ or medical record review. All control women were mothers of typically developing children who had not been diagnosed or treated for any developmental delays or disorders, and $70 \%$ of controls completed genetic testing to rule out the FMRI premutation through dual enrollment in a related pilot study.

Women with the FMRI premutation were recruited through word of mouth and social media targeting local families, or through their children who were participating in developmental studies of fragile $\mathrm{X}$ syndrome with nation-wide recruitment. Control women were recruited locally through flyers posted at pediatrician offices, word of mouth, and social media. The sample was primarily Caucasian (92\% of the FMR1 premutation group; $86 \%$ of controls). The groups did not differ on age, IQ, or education level. Chronic stress can influence the integrity of physiological regulation systems (McEwen 1998), so information on parenting stress was collected and tested as a potential confound; as expected, the FMR1 premutation group reported higher levels of parenting stress (see Table 1 for demographic information). 
Table 1 Group characteristics

\begin{tabular}{|c|c|c|c|}
\hline \multirow[t]{2}{*}{ Variable } & \multicolumn{3}{|l|}{ Group } \\
\hline & $\begin{array}{l}\text { FMRl premutation } \\
(n=38)\end{array}$ & $\begin{array}{l}\text { Control } \\
(n=23)\end{array}$ & $\begin{array}{l}\text { Test of } \\
\text { group differ- } \\
\text { ences } \\
\text { ( } p \text {-value) }\end{array}$ \\
\hline \multicolumn{4}{|l|}{ Age in years } \\
\hline$M(S D)$ & $44.51(8.61)$ & $42.16(7.99)$ & \multirow[t]{2}{*}{0.293} \\
\hline Range & $25.53-59.96$ & $33.10-64.02$ & \\
\hline \multicolumn{4}{|l|}{$\mathrm{IQ}^{\mathrm{a}}$} \\
\hline$M(S D)$ & $105.35(12.90)$ & $106.26(11.03)$ & \multirow[t]{2}{*}{0.800} \\
\hline Range & $81.00-130.00$ & $83.00-135.00$ & \\
\hline \multicolumn{4}{|l|}{ Education level (\%) } \\
\hline High school or lower & 47 & 26 & \multirow[t]{4}{*}{0.221} \\
\hline Bachelor's degree & 29 & 30 & \\
\hline Master's degree & 24 & 26 & \\
\hline Professional degree & 0 & 17 & \\
\hline \multicolumn{4}{|l|}{ Medication use (\%) } \\
\hline Atypical antipsychotics & 3 & 0 & \multirow[t]{7}{*}{$0.018^{*}$} \\
\hline Classical antipsychotics & 3 & 0 & \\
\hline Antidepressants & 36 & 0 & \\
\hline Mood stabilizers & 6 & 0 & \\
\hline Stimulants & 3 & 4 & \\
\hline Antianxiety & 0 & 0 & \\
\hline Anticonvulsants & 3 & 0 & \\
\hline \multicolumn{4}{|l|}{ Parenting stress percentile ${ }^{b}$} \\
\hline$M(S D)$ & $58.39(22.33)$ & $36.82(23.44)$ & \multirow[t]{2}{*}{$0.001 *$} \\
\hline Range & $4.00-96.00$ & $1.00-82.00$ & \\
\hline
\end{tabular}

Information on medication use was collected given that certain psychotropic medication can influence cardiac activity, although the direction and magnitude of the relationship is complex and varies across individuals (O'Brien and Oyebode 2003). In a recent systematic review and metanalysis of psychotropic medications, only tricyclic antidepressants and clozapine were found to have a statistically significantly influence heart rate variability (Alvares et al. 2016); none of the participants in the present sample were taking either clozapine or tricyclic antidepressants. More women with the FMRI premutation than control women used one or more psychotropic medications (42\% vs. 13\%); psychotropic medication use was covaried in analyses. Information on the use of other cardioactive medications (e.g., beta blockers) was also collected. Two control participants reporting using an antihypertensive medication. Results were the same when these participants were excluded, so these participants were retained in analyses.

\section{Procedure}

Participants provided informed consent and all procedures were approved by the Institutional Review Board of the University of South Carolina. Baseline vagal tone was sampled after consent was obtained and before the initiation of other assessment activities. The conversational sample was collected approximately an hour into the research protocol.

\section{Measures}

\section{Vagal Tone}

Baseline vagal tone was measured from a 3-min resting condition in which participants viewed a video of an ocean scene. An Actiwave Cardio monitor (CamNtech Ltd., Cambridge, 
UK) sampled the ECG signal at $1024 \mathrm{~Hz}$ via two electrodes placed on the participant's chest. The IBI series was extracted using QRSTool (Allen et al. 2007). Artifacts and arrhythmias were edited with CardioEdit software (Porges 1985; Porges and Bohrer 1990), with all files requiring $<5 \%$ correction. Mean respiratory sinus arrhythmia (RSA), an index of vagal tone, was extracted using CardioBatch (Porges and Bohrer 1990) with a $0.12-0.40 \mathrm{~Hz}$ bandpass filter.

\section{Pragmatic Language}

Participants engaged in a 20 min conversational interaction with an examiner that was guided by a series of probe questions intended to elicit conversation on familiar, shared experiences (e.g., "What did you enjoy most during your time in high school?"). To ensure opportunities for conversational back-andforth, examiners were trained to comment, offer information, and ask follow-up questions. The samples were videotaped and coded off-line for pragmatic violations using a modified version of the Pragmatic Rating Scale (Landa et al. 1992), which has been used to capture pragmatic variation in non-disordered adults (see Klusek et al. 2014; Losh et al. 2012). The scale captures 26 possible pragmatic language violations that are coded on a scale of $0-2$ based on operational definitions of the frequency or severity of each violation. A total score is computed by summing individual items, with a higher score reflecting greater pragmatic difficulty. Each videotaped sample was coded by two independent raters and consensus scores were produced through discussion. Rater 1 was unable to remain blind to group membership due to her role in participant assessment; rater 2 was blind to the group membership of all participants. Prior to consensus, inter-rater reliability was $\operatorname{ICC}(3,2)=0.72$, which is considered "good" agreement (Cicchetti 2001).

\section{Results}

\section{Descriptive Statistics and Preliminary Analyses}

Descriptive statistics were computed (see Table 2) and the data were examined for normality, with no corrections

Table 2 Descriptive statistics

\begin{tabular}{lll}
\hline Variable & Group & \\
\cline { 3 - 3 } & FMRl premutation & Control \\
\hline Vagal tone & \\
$M(S D)$ & $4.90(1.32)$ & $5.69(1.00)$ \\
Range & $1.78-7.64$ & $2.88-7.26$ \\
Pragmatic Rating Scale score & \\
$M(S D)$ & $9.42(3.94)$ & $5.00(3.03)$ \\
Range & $2.00-17.00$ & $0-11.00$ \\
\hline
\end{tabular}

necessary. Pearson correlations tested potential confounds to inform the final statistical models. No associations were detected between parenting stress and vagal tone within or across the groups (all $r$ 's $<.09$, all $p$ 's $>0.629$ ). Parenting stress level was also not associated with pragmatic skills within or across groups (all $r$ 's $<.21$, all $p$ 's $>0.253$ ). Within the groups, there were no differences between the vagal tone of individuals who were or were not using medication (all $p$ 's $>0.304$ ); a trend for lower vagal tone in medicated individuals was detected when the groups were collapsed $(p=0.067)$. Based on these preliminary analyses, psychotropic medication use (coded as present or absent) was integrated as a covariate in the models including vagal tone, to control for psychotropic medication use as a potential confounder of results. We did not control for parenting stress level in the final models given that preliminary analyses did not support an association. The groups differed on mean vagal tone estimates, with reduced vagal tone in the $F M R 1$ premutation group relative to controls $(p=0.016$, $\left.\eta_{p}^{2}=0.09\right)$.

\section{Group Differences in Pragmatic Ability}

A general linear model tested group as a predictor of the Pragmatic Rating Scale score. Pragmatic language difficulties were elevated in women with the $F M R 1$ premutation $(F$ $[1,59]=21.26, p<0.001)$, with partial eta squared $\left(\eta_{p}^{2}\right)$ of 0.27 consistent with a "large" effect size (Cohen 1988). Group differences are presented in Fig. 2.

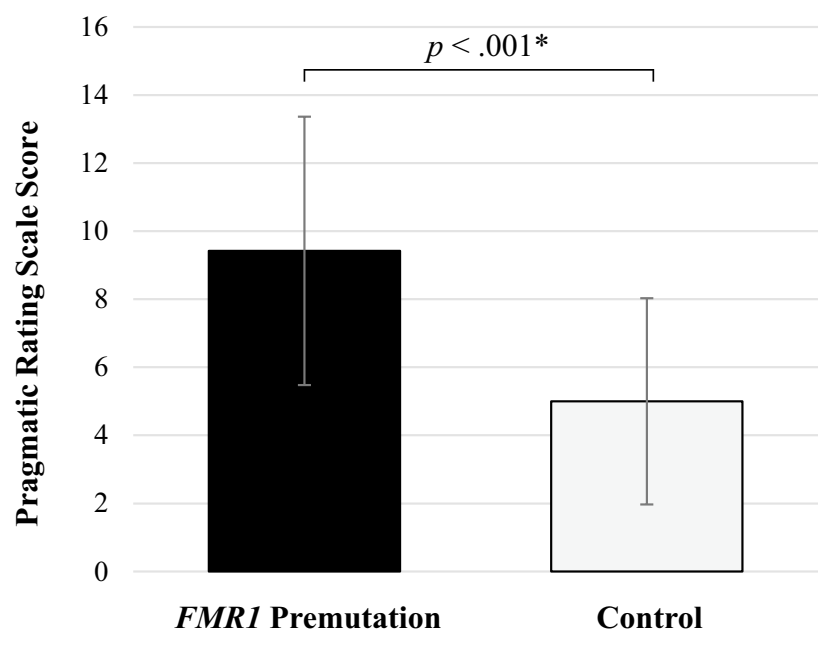

Fig. 2 Group differences in pragmatic language competence. A higher score on the Pragmatic Rating Scale indicates increased pragmatic language difficulties 


\section{The Indirect Effect of FMR1 Premutation Group Membership on Pragmatics via Vagal Tone}

Prior to conducting statistical mediation analysis, we confirmed that there was no interaction between the independent variable (group membership) and the mediator variable (vagal tone), which is a statistical assumption of mediation models (MacKinnon et al. 2007). To test this assumption, we fit a general linear model including group, vagal tone, and their interaction as predictors of pragmatic ability, with medication use included as a covariate. A main effect for vagal tone was detected, where higher vagal tone was associated with increased pragmatic competence $(F$ $\left.[1,56]=4.83, p=0.032, \eta_{p}^{2}=0.08\right)$. The group-by-vagal tone interaction term was not significant $(F[1,56]=0.28$, $\left.p=0.597, \eta_{p}^{2}<0.01\right)$, indicating that the association between vagal tone and pragmatics did not differ according to group. In this model, the main effects for group $(F[1,56]=1.63$, $\left.p=0.201, \eta_{p}^{2}=0.03\right)$ and medication use $(F[1,56]=0.36$, $\left.p=0.550, \eta_{p}^{2}=0.01\right)$ were also not significant.

Next, a formal statistical test of mediation evaluated the putative pathway where the $F M R 1$ premutation genetic status impacts pragmatic ability via dampened vagal tone. Mediation analyses were conducted using the product of coefficients approach with bias-corrected bootstrapping for significance testing, as research supports that this test of mediation as more powerful relative to other options (Fritz and MacKinnon 2007) and does not make assumptions about the shape of the sampling distribution of the indirect effect (MacKinnon et al. 2004; Shrout and Bolger 2002). Further, the approach has been shown to coincide with causal inference approaches to mediation when there is no interaction of the independent and mediator variables, as demonstrated here, and the outcome is continuous (Valeri and VanderWeele 2013). In the product of coefficients approach, the presence of a mediating mechanism is established through assessing statistical significance of the indirect effect of the independent variable on the dependent variable through the mediator variable, using path tracing rules introduced in the early structural equation modeling literature (see Fairchild and McDaniel 2017, for review).

Analyses were conducted with the PROCESSv2.16 macro (Hayes 2012) for IBM SPSS Statistics (SPSS 2012). Although a limitation of PROCESS can be its use of listwise deletion to handle missing data, this was not a concern for our dataset, which had complete data for all participants. A single mediator model was specified to test the indirect effect of group membership on pragmatic ability via vagal tone, controlling for medication use. A 95\% confidence interval was calculated for the indirect effect using 5000 bootstrap samples. Results yielded a significant indirect effect point estimate of $a b=0.71$ with a corresponding $95 \%$ bias-corrected, bootstrapped confidence interval equal to $[0.04$,

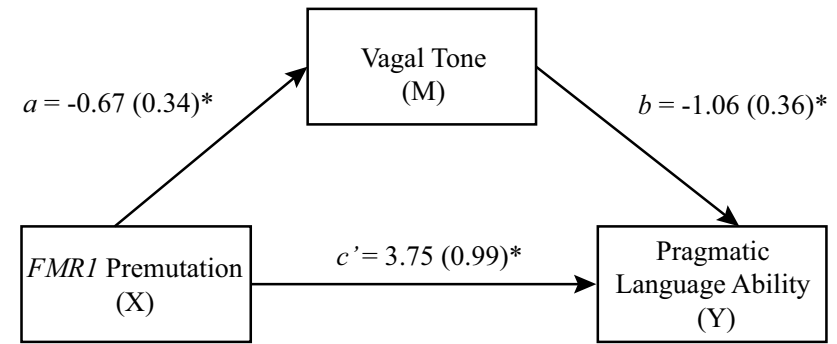

Paramenter Estimates

of Mediation:

$a b=0.71(0.50)^{*}$, CI 95\% [0.04, 2.08]

Fig. 3 The indirect effect of FMRI premutation status on pragmatic language ability through vagal tone. Parameter estimates are controlling for medication use. $X$ independent variable, $M$ mediator, $Y$ dependent variable. $a b$ represents the indirect effect of $\mathrm{X}$ on $\mathrm{Y}$ through the mediating variable. ${ }^{*} p<0.05$

Table 3 Correlations with CGG repeat length within the FMR1 premutation group

\begin{tabular}{lccl}
\hline & $\begin{array}{l}\text { CGG } \\
\text { repeat } \\
\text { length }\end{array}$ & Vagal tone & $\begin{array}{l}\text { Pragmatic } \\
\text { Rating Scale } \\
\text { score }\end{array}$ \\
\hline CGG repeat length & 1.00 & & \\
Vagal tone & $0.37^{*}$ & 1.00 & \\
Pragmatic Rating Scale score & -0.17 & $-0.37^{*}$ & 1.00 \\
\hline
\end{tabular}

Partial correlations are presented, covarying for medication use $* p<0.05$

2.08], supporting vagal tone as a partial mediator underlying the relation between $F M R 1$ premutation genetic status and pragmatic ability. Unstandardized parameter estimates for the model are shown in Fig. 3.

\section{Associations with FMR1 CGG Repeat Length}

Finally, to investigate ties with FMRI molecular genetic indices, we conducted exploratory correlations between CGG repeat length, vagal tone, and pragmatic language scores in the FMRl premutation group ${ }^{1}$. Partial Pearson correlations were conducted, covarying for medication use. The length of the expanded CGG sequence was significantly associated with vagal tone $(r=0.37, p=0.036)$ but not pragmatic language skills $(r=-0.17, p=0.362)$, see Table 3 .

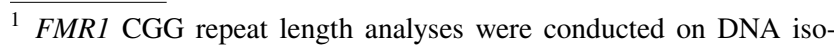
lated from either peripheral blood lymphocytes using standard methods (Qiagen, Valencia, CA) or whole blood dried blood spots (Adayev et al. 2014), using polymerase chain reaction and Southern Blot (Filipovic-Sadic et al. 2010; Tassone et al. 2008).
} 


\section{Discussion}

Investigations into the roots of pragmatic language impairment are timely. The autism epidemic has thrust pragmatic language impairment into the limelight, leading to increased awareness of the significant social, behavioral, and psychological consequences of pragmatic language impairment, and spurring the recent recognition of Social (Pragmatic) Communication Disorder as its own diagnostic category in DSM-5 (American Psychiatric Association 2013). This study investigated vagal tone, an index of parasympathetic "rest and digest" autonomic function, as a biophysiological pathway tied to pragmatic competence. We focused on the FMRI premutation as a genetic condition that may lend insight into mechanistic underpinnings of pragmatics that may generalize to other groups. Consistent with Polyvagal Theory, high vagal tone was associated with enhanced pragmatic competence in both women with the FMR1 premutation and neurotypical women. Statistical mediation analysis indicated that the impact of FMR1 premutation genetic status on pragmatic ability was carried through dampened vagal tone. This study opens new lines of inquiry into the physiological correlates of pragmatic ability that may be shared across the spectrum of pragmatic skills seen in both typical and atypical populations.

\section{Vagal Tone as a Biomarker for Pragmatic Competence}

Given the wide variability in the clinical effects of the FMR1 premutation, a major challenge to its clinical management is the lack of useful biomarkers that can lead to breakthroughs in the development of prevention/treatment efforts for this condition. Vagal tone is a promising potential biomarker because it is a quantitative, heritable trait that is established prenatally and shows within-individual stability across developmental periods (Calkins and Keane 2004; Doussard-Roosevelt et al. 2003; El-Sheikh 2005; Fracasso et al. 1994; Kleiger et al. 1991; Kupper et al. 2005). It can also be indexed reliably and non-invasively, making its application in clinical settings feasible. The present study provides preliminary support for vagal tone as a biomarker for pragmatic language deficits. We found, via statistical mediation analysis, that the impact of $F M R 1$ premutation carrier status on pragmatic language ability was carried through vagal tone. More work is needed for formal biomarker validation, which requires evidence of causal relationships between the putative biomarker and disease traits (Bonassi et al. 2001). We cannot infer causality from our cross-sectional design. Findings are nevertheless important, however, because they inform variability in the putative biomarker within population subgroups, contributing to the initial stages of biomarker validation.
Notably, prior research has failed to detect an association between dampened vagal tone and symptoms of anxiety and depression in women with the FMRI premutation (Klusek et al. 2017a). Thus, there appears to be a level of specificity, where only select features of the FMRI premutation phenotype are associated with dampened vagal tone. Findings suggest that the inclusion of vagal indices in future work may enhance understanding of $F M R 1$ genebehavior associations by revealing indirect pathways that may mediate relationships.

A remaining question regards the specific $F M R I$-associated mechanisms driving the relationship between FMRI premutation group membership, vagal tone, and pragmatic ability. We lacked the sample size necessary to conduct formal mediation analyses testing putative pathways linking CGG repeat length, vagal tone, and pragmatics. However, our preliminary analyses did indicate an association between the size of the CGG expansion and vagal tone in the FMRI premutation group. Yet, CGG length was not correlated with pragmatic ability. Follow-up work in larger samples is needed to fully understand the nature of these relationships, as we may have been underpowered to detect small effects. Additionally, CGG length is only one indicator of FMRI gene function and other FMRI molecular genetic indices may be more closely linked with phenotypic variation. In particular, FMRI mRNA is of interest given its relationship with vagal tone detected in prior work (Klusek et al. 2017a).

Findings also support further investigation into the utility of vagal tone as a surrogate endpoint, or an "intermediate pathway" that may predict change in clinical endpoints. Despite major advances in understanding of the biology of FMRI conditions, the translation of molecular targets into therapeutics has been slowed by the lack of biomarkers that can sensitively index the impact of a new treatment on specific biological mechanisms that are correlated with clinical outcomes (see Jacquemont et al. 2014, for review). Vagal tone may be considered as a potential surrogate endpoint in future work because it is theoretically and empirically linked with core aspects of the phenotype and is associated with FMR1 molecular genetic indices (Klusek et al. 2017a). There is also some evidence from the study of other clinical groups that vagal improvements may map onto positive behavior change, although findings are preliminary (Bagner et al. 2009; Graziano et al. 2012; Porges et al. 2013). The present study establishes an initial association between vagal tone and pragmatic language ability, suggesting that further validation work of vagal tone as a potential surrogate endpoint in FMRl conditions may be a fruitful direction.

It is notable that the detected association between vagal tone and pragmatic ability was not specific to the FMRI premutation; vagal tone accounted for pragmatic variability in the neurotypical controls as well. Thus, vagal tone could play a general mechanistic role in pragmatic language competence 
that is relevant to both typical and atypical development. This generalizability across groups strengthens the potential utility of vagal tone as a biomarker for pragmatic language deficits. Modern conceptualizations of biomarkers recognize that biological underpinnings can cross diagnostic boundaries, which is consistent with frameworks such as the RDoC that emphasize dimensional-trait models that span the clinical and non-clinical spectrum (see Beauchaine and Thayer 2015 for discussion of transdiagnostic biomarkers). The detected association between vagal tone and pragmatics in control women (who did not carry premutation alleles on FMRI) does not preclude a role of FMRI in vagal regulation. Historically, FMRI has been studied almost exclusively within the context of fragile $\mathrm{X}$-associated disorders, however, over the last decade it has become increasingly evident that FMRI is also highly important at the population level. Individuals in the general population, who do not carry abnormalities on FMR1, nevertheless show normal variability in the length of the CGG sequence, as well as in the expression of FMRI mRNA and FMR1 protein (Chen et al. 2003; Ludwig et al. 2011; Peprah 2012; Tassone et al. 2011; Wang et al. 2013). New evidence suggests that normal variation in these FMRI molecular genetic indices is associated with phenotypic variability in the general population, including associations with cognitive function and brain structure (Adamsheck et al. 2017; Mailick et al. 2014, 2017; Wang et al. 2013; Weghofer et al. 2012). Moreover, FMRI can effect widespread changes in background gene expression via its involvement in the translational regulation of over 800 other genes, which include onethird to one-half of the genes identified as ASD susceptibility genes (Darnell and Klann 2013; Darnell et al. 2011; Iossifov et al. 2012) as well as several genes implicated in autonomic regulation, such as BDNF and CRHRI (Allegrini et al. 2017; Gatt et al. 2009; Sumner et al. 2015; Yang et al. 2010). Thus, it is possible that $F M R 1$ gene function could relate to autonomic health in the general population and in other non-fragile $X$ clinical groups, either through the direct effects of FMRl or via background gene interactions.

\section{Limitations and Directions}

It is important to note that our cross-sectional design can only assume that the direction of influence was from vagal tone to pragmatic language. Our temporal assumption of variable ordering in the model is grounded in theory (i.e., Polyvagal Theory) and supported by empirical evidence that vagal tone is a heritable neurophysiological substrate that is established early in life (Calkins and Keane 2004; Doussard-Roosevelt et al. 2003; El-Sheikh 2005; Fracasso et al. 1994). Additionally, in fragile $X$ syndrome, vagal dysfunction emerges in infancy and is therefore understood to represent a biological signature of $F M R l$ gene dysfunction, rather than a trait that emerges as a result of environmental factors (Roberts et al. 2012). However, our design prevents causal inferences and follow-up investigations are needed to confirm the presumed direction of effects.

There are some limitations related to the sample, such as lack of racial diversity, which may limit generalization of our findings. Also, our sample focused on women with the FMRl premutation who had a child with fragile $\mathrm{X}$ syndrome. While we did not detect any associations between parenting stress level and pragmatic skills or vagal tone, we are unable to completely parse out the stressors associated with parenting a child with a disability from the specific effects of the FMR1 premutation. Future directions include investigation into the trajectory, developmental timing, and mechanisms of pragmatic language difficulties in early childhood, when intervention efforts may have the largest effects. Study strengths include the use of the Pragmatic Rating Scale, which provides a sensitive direct observation method for capturing pragmatic language ability across the normal and impaired range, as well as investigating mediation hypotheses of underlying mechanisms of pragmatic language.

\section{Conclusion}

Focusing on the FMRl premutation as a genetic model for pragmatic language deficits, we found support for vagal tone as a biophysiological correlate of pragmatic ability across both women with the FMR1 premutation as well as neurotypical controls. Statistical mediation analysis supported vagal tone as a mediator of the relationship between FMRI premutation genetic status and pragmatic language ability. Overall, findings suggest a link between healthy vagal function and social communication competence and point towards vagal tone as a biological factor that may relate to pragmatic problems in other clinical groups, such as ASD.

Acknowledgments We would like to thank the women who participated in this study.

Author Contributions JK conceived the study, led the data collection, analysis, interpretation, and drafted the manuscript. AJF provided consultation on the statistical models. JER provided guidance on the study design, data collection, and interpretation. All authors contributed to the interpretation of results and critical revising of the manuscript. All authors read and approved the final manuscript.

Funding This study was funded by the National Institutes of Health (F32DC013934; R01MH090194; R01HD024356; U54HD079125, R01HD02274), the Research Participant Registry Core of the Carolina Institute for Developmental Disabilities (P30HD03110), and an ASPIRE grant from the Office of the Vice President for Research at the University of South Carolina. 


\section{Compliance with Ethical Standards}

Conflict of interest The authors declare that they have no conflict of interest.

Ethical Approval All procedures performed in studies involving human participants were in accordance with the ethical standards of the institutional and with the 1964 Helsinki declaration and its later amendments.

Informed Consent Informed consent was obtained from all individual participants included in the study.

\section{References}

Abidin, R. R. (2013). Parenting Stress Index, Fourth Edition Short Form (PSI-4-SF). Lutz: PAR, Inc.

Adamsheck, H. C., Petty, E. M., Hong, J., Baker, M. W., Brilliant, M. H., \& Mailick, M. R. (2017). Is low FMR1 CGG repeat length in males correlated with family history of BRCA-associated cancers? An exploratory analysis of medical records. Journal of Genetic Counseling. https://doi.org/10.1007/s10897-017-0116-5.

Adayev, T., LaFauci, G., Dobkin, C., Caggana, M., Wiley, V., Field, M., et al. (2014). Fragile X protein in newborn dried blood spots. BMC Medical Genetics, 15(1), 119. https://doi.org/10.1186/s1288 1-014-0119-0.

Allegrini, A. G., Evans, B. E., de Rooij, S., Greaves-Lord, K., \& Huizink, A. C. (2017). Gene $\times$ Environment contributions to autonomic stress reactivity in youth. Development and Psychopathology. https://doi.org/10.1017/S095457941700181X.

Allen, J. J., Chambers, A. S., \& Towers, D. N. (2007). The many metrics of cardiac chronotropy: A pragmatic primer and a brief comparison of metrics. Biological Psychology, 74(2), 243-262.

Alvares, G. A., Quintana, D. S., Hickie, I. B., \& Guastella, A. J. (2016). Autonomic nervous system dysfunction in psychiatric disorders and the impact of psychotropic medications: A systematic review and meta-analysis. Journal of Psychiatry Neuroscience, 41, 89-104.

American Psychiatric Association. (2013). Diagnostic and statistical manual of mental disorders (5th ed.). Arlington: American Psychiatric Publishing Incorporated.

Bagner, D. M., Sheinkopf, S. J., Miller-Loncar, C. L., Vohr, B. R., Hinckley, M., Eyberg, S. M., \& Lester, B. M. (2009). Parent-child interaction therapy for children born premature: A case study and illustration of vagal tone as a physiological measure of treatment outcome. Cognitive and Behavioral Practice, 16(4), 468-477. https://doi.org/10.1016/j.cbpra.2009.05.002.

Beauchaine, T. P., \& Thayer, J. F. (2015). Heart rate variability as a transdiagnostic biomarker of psychopathology. International Journal of Psychophysiology, 98(2), 338-350.

Bishop, D. V., \& Norbury, C. F. (2002). Exploring the borderlands of autistic disorder and specific language impairment: A study using standardised diagnostic instruments. Journal of Child Psychology and Psychiatry, 43(7), 917-929.

Bonassi, S., Neri, M., \& Puntoni, R. (2001). Validation of biomarkers as early predictors of disease. Mutation Research/Fundamental and Molecular Mechanisms of Mutagenesis, 480, 349-358.

Brook, S. L., \& Bowler, D. M. (1992). Autism by another name? Semantic and pragmatic impairments in children. Journal of Autism and Developmental Disorders, 22(1), 61-81.

Brown, S. S., \& Stanfield, A. C. (2015). Fragile X premutation carriers: A systematic review of neuroimaging findings. Journal of the Neurological Sciences, 352(1), 19-28.
Calkins, S. D., \& Keane, S. P. (2004). Cardiac vagal regulation across the preschool period: Stability, continuity, and implications for childhood adjustment. Developmental Psychobiology, 45(3), 101-112. https://doi.org/10.1016/j.biopsycho.2006.09.005.

Chen, L.-S., Tassone, F., Sahota, P., \& Hagerman, P. J. (2003). The (CGG) $n$ repeat element within the 5' untranslated region of the FMR1 message provides both positive and negative cis effects on in vivo translation of a downstream reporter. Human Molecular Genetics, 12(23), 3067-3074. https://doi.org/10.1093/hmg/ddg331.

Cicchetti, D. V. (2001). Methodological commentary the precision of reliability and validity estimates re-visited: Distinguishing between clinical and statistical significance of sample size requirements. Journal of Clinical and Experimental Neuropsychology, 23(5), 695-700.

Clifford, S., Dissanayake, C., Bui, Q. M., Huggins, R., Taylor, A. K., \& Loesch, D. Z. (2007). Autism spectrum phenotype in males and females with fragile $\mathrm{X}$ full mutation and premutation. Journal of Autism and Developmental Disorders, 37(4), 738-747. https://doi. org/10.1007/s10803-006-0205-z.

Cohen, J. (1988). Statistical power analysis for the behavioral sciences. Hillsdale: L. Erlbaum Associates.

Conti-Ramsden, G., Botting, N., \& Knox, E. (2001). Follow-up of children attending infant language units: Outcomes at 11 years of age. International Journal of Language and Communication Disorders, 36(2), 207-219.

Coplan, R. J., \& Weeks, M. (2009). Shy and soft-spoken: Shyness, pragmatic language, and socio-emotional adjustment in early childhood. Infant and Child Development, 18(3), 238-254.

Darnell, J. C., \& Klann, E. (2013). The translation of translational control by FMRP: Therapeutic targets for FXS. Nature Neuroscience, 16(11), 1530-1536. https://doi.org/10.1038/nn.3379.

Darnell, J. C., Van Driesche, S. J., Zhang, C., Hung, K. Y., Mele, A., Fraser, C. E., et al. (2011). FMRP stalls ribosomal translocation on mRNAs linked to synaptic function and autism. Cell, 146(2), 247-261. https://doi.org/10.1016/j.cell.2011.06.013.

Demaree, H. A., Robinson, J. L., Everhart, E., \& Schmeichel, B. J. (2004). Resting RSA is associated with natural and self-regulated responses to negative emotional stimuli. Brain and Cognition, 56(1), 14-24. https://doi.org/10.1016/j.bandc.2004.05.001.

Doussard-Roosevelt, J. A., Montgomery, L. A., \& Porges, S. W. (2003). Short-term stability of physiological measures in kindergarten children: Respiratory sinus arrhythmia, heart period, and cortisol. Developmental Psychobiology, 43(3), 230-242. https://doi. org/10.1002/dev.10136.

El-Sheikh, M. (2005). Stability of respiratory sinus arrhythmia in children and young adolescents: A longitudinal examination. Developmental Psychobiology, 46(1), 66-74. https://doi.org/10.1002/ dev.20036.

Fairchild, A. J., \& McDaniel, H. L. (2017). Best (but oft-forgotten) practice: Mediation analysis. American Journal of Clinical Nutrition, 105, 1259-1271.

Filipovic-Sadic, S., Sah, S., Chen, L., Krosting, J., Sekinger, E., Zhang, W., et al. (2010). A novel FMR1 PCR method for the routine detection of low abundance expanded alleles and full mutations in fragile X syndrome. Clinical Chemistry, 56(3), 399-408. https ://doi.org/10.1373/clinchem.2009.136101.

Fracasso, M. P., Porges, S. W., Lamb, M. E., \& Rosenberg, A. A. (1994). Cardiac activity in infancy: Reliability and stability of individual differences. Infant Behavior and Development, 17(3), 277-284. https://doi.org/10.1016/0163-6383(94)90006-X.

Fritz, M. S., \& MacKinnon, D. P. (2007). Required sample size to detect the mediated effect. Psychological Science, 18(3), 233-239.

Gatt, J., Nemeroff, C., Dobson-Stone, C., Paul, R., Bryant, R., Schofield, P., et al. (2009). Interactions between BDNF Val66Met polymorphism and early life stress predict brain and arousal pathways 
to syndromal depression and anxiety. Molecular Psychiatry, 14(7), 681

Geurts, H. M., Verté, S., Oosterlaan, J., Roeyers, H., Hartman, C. A., Mulder, E. J., et al. (2004). Can the Children's Communication Checklist differentiate between children with autism, children with ADHD, and normal controls? Journal of Child Psychology and Psychiatry, 45(8), 1437-1453.

Graziano, P. A., Bagner, D. M., Sheinkopf, S. J., Vohr, B. R., \& Lester, B. M. (2012). Evidence-based intervention for young children born premature: Preliminary evidence for associated changes in physiological regulation. Infant Behavior and Development, 35(3), 417-428. https://doi.org/10.1016/j.infbeh.2012.04.001.

Hagerman, R., \& Hagerman, P. (2013). Advances in clinical and molecular understanding of the FMR1 premutation and fragile $\mathrm{X}$-associated tremor/ataxia syndrome. The Lancet Neurology, 12(8), 786-798. https://doi.org/10.1016/S1474-4422(13)70125-X.

Hayes, A. F. (2012). PROCESS: A versatile computational tool for observed variable mediation, moderation, and conditional process modeling. In: University of Kansas, KS.

Hessl, D., Rivera, S., Koldewyn, K., Cordeiro, L., Adams, J., Tassone, F., et al. (2007). Amygdala dysfunction in men with the fragile $\mathrm{X}$ premutation. Brain, 130, 404-416.

Hessl, D., Wang, J. M., Schneider, A., Koldewyn, K., Le, L., Iwahashi, C., et al. (2011). Decreased FMRP expression underlies amygdala dysfunction in carriers of the fragile $\mathrm{X}$ premutation. Biological Psychiatry, 70(9), 859-865. https://doi.org/10.1016/j. biopsych.2011.05.033.

Insel, T. R. (2014). The NIMH research domain criteria (RDoC) project: Precision medicine for psychiatry. American Journal of Psychiatry, 171(4), 395-397. https://doi.org/10.1176/appi. ajp.2014.14020138.

Iossifov, I., Ronemus, M., Levy, D., Wang, Z., Hakker, I., Rosenbaum, J., et al. (2012). De novo gene disruptions in children on the autistic spectrum. Neuron, 74(2), 285-299. https://doi.org/10.1016/j. neuron.2012.04.009.

Jacquemont, S., Berry-Kravis, E., Hagerman, R., von Raison, F., Gasparini, F., Apostol, G., et al. (2014). The challenges of clinical trials in fragile X syndrome. Psychopharmacology (Berl), 231(6), 1237-1250. https://doi.org/10.1007/s00213-013-3289-0.

Jobe, L. E., \& White, S. W. (2007). Loneliness, social relationships, and a broader autism phenotype in college students. Personality and Individual Differences, 42(8), 1479-1489. https://doi. org/10.1016/j.paid.2006.10.021.

Kaufman, A. S., \& Kaufman, N. L. (2004). Kaufman brief intelligence test (2nd ed.). Los Angeles: Pearson Assessments.

Ketelaars, M. P., Cuperus, J., Jansonius, K., \& Verhoeven, L. (2010). Pragmatic language impairment and associated behavioural problems. International Journal of Language and Communication Disorders, 45(2), 204-214.

Kleiger, R. E., Bigger, J. T., Bosner, M. S., Chung, M. K., Cook, J. R., Rolnitzky, L. M., et al. (1991). Stability over time of variables measuring heart rate variability in normal subjects. The American Journal of Cardiology, 68(6), 626-630.

Klusek, J., Losh, M., \& Martin, G. (2014). Sex differences and withinfamily associations in the broad autism phenotype. Autism: International Journal of Research and Practice, 18, 106-116. https:// doi.org/10.1177/1362361312464529.

Klusek, J., Martin, G. E., \& Losh, M. (2013). Physiological arousal in autism and fragile $\mathrm{X}$ syndrome: Group comparisons and links with pragmatic language. American Journal on Intellectual and Developmental Disabilities, 118(6), 475-495. https://doi. org/10.1352/1944.7558-118.6.475.

Klusek, J., Martin, G. E., \& Losh, M. (2014). A comparison of pragmatic language in boys with autism and fragile $X$ syndrome. Journal of Speech, Language, and Hearing Research,
57, 1692-1707. https://doi.org/10.1044/2014_JSLHR -L-13-0064.

Klusek, J., McGrath, S. E., Abbeduto, L., \& Roberts, J. E. (2016). Pragmatic language features of mothers with the FMR1 premutation are associated with the language outcomes of adolescents and young adults with fragile X syndrome. Journal of Speech, Language, and Hearing Research, 59, 49-61. https ://doi.org/10.1044/2015_JSLHR-L-15-0102.

Klusek, J., Roberts, J. E., \& Losh, M. (2015). Cardiac autonomic regulation in autism and fragile $\mathrm{X}$ syndrome: A review. Psychological Bulletin, 141, 141-175.

Klusek, J., LaFauci, G., Adayev, T., Brown, W. T., Tassone, F., \& Roberts, J. (2017a). Reduced vagal tone in women with the $F M R 1$ premutation is associated with FMR1 mRNA but not depression or anxiety. Journal of Neurodevelopmental Disorders, 9, 1-16.

Klusek, J., Ruber, A., \& Roberts, J. E. (2017b). Impaired eye contact in the FMR1 premutation is not associated with social anxiety or the broad autism phenotype. The Clinical Neuropsychologist, 3, 1-16. https://doi.org/10.1080/13854046.2017.1384063.

Klusek, J., Schmidt, J., Fairchild, A. J., Porter, A., \& Roberts, J. E. $(2017 \mathrm{c})$. Altered sensitivity to social gaze in the $F M R 1$ premutation and pragmatic language competence. Journal of Neurodevelopmental Disorders, 9, 1-10.

Kok, B. E., \& Fredrickson, B. L. (2010). Upward spirals of the heart: Autonomic flexibility, as indexed by vagal tone, reciprocally and prospectively predicts positive emotions and social connectedness. Biological Psychology, 85(3), 432-436.

Kupper, N., Willemsen, G., Posthuma, D., De Boer, D., Boomsma, D. I., \& De Geus, E. J. (2005). A genetic analysis of ambulatory cardiorespiratory coupling. Psychophysiology, 42(2), 202-212. https://doi.org/10.1111/j.1469-8986.2005.00276.x.

Landa, R. (2000). Social language use in Asperger syndrome and high-functioning autism. In K. Ami, F. Volkmar \& S. S. Sparrow (Eds.), Asperger syndrome (pp. 403-417). New York: Guilford Press.

Landa, R., Piven, J., Wzorek, M. M., Gayle, J. O., Chase, G. A., \& Folstein, S. E. (1992). Social language use in parents of autistic individuals. Psychological Medicine, 22(1), 245-254.

Laws, G., Bates, G., Feuerstein, M., Mason-Apps, E., \& White, C. (2012). Peer acceptance of children with language and communication impairments in a mainstream primary school: Associations with type of language difficulty, problem behaviours and a change in placement organization. Child Language Teaching and Therapy, 28(1), 73-86. https://doi.org/10.1177/0265659011 419234.

Losh, M., Childress, D., Lam, K., \& Piven, J. (2008). Defining key features of the broad autism phenotype: A comparison across parents of multiple- and single-incidence autism families. American Journal of Medical Genetics Part B: Neuropsychiatric Genetics, 147B(4), 424-433. https://doi.org/10.1002/ajmg.b.30612.

Losh, M., Klusek, J., Martin, G. E., Sideris, J., Parlier, M., \& Piven, J. (2012). Defining genetically meaningful language and personality traits in relatives of individuals with fragile $\mathrm{X}$ syndrome and relatives of individuals with autism. American Journal of Medical Genetics Part B: Neuropsychiatric Genetics, 159B(6), 660-668. https://doi.org/10.1002/ajmg.b.32070.

Losh, M., Martin, G. E., Klusek, J., Hogan-Brown, A. L., \& Sideris, J. (2012). Social communication and theory of mind in boys with autism and fragile X syndrome. Frontiers in Psychology, 3, 1-12. https://doi.org/10.3389/fpsyg.2012.00266.

Ludwig, A. L., Hershey, J. W., \& Hagerman, P. J. (2011). Initiation of translation of the FMR $1 \mathrm{mRNA}$ Occurs predominantly through 5 '-end-dependent ribosomal scanning. Journal of Molecular Biology, 407(1), 21-34. https://doi.org/10.1016/j.jmb.2011.01.006. 
MacKinnon, D. P., Fairchild, A. J., \& Fritz, M. S. (2007). Mediation analysis. Annual Review of Psychology, 58, 593. https://doi. org/10.1146/annurev.psych.58.110405.085542.

MacKinnon, D. P., Lockwood, C. M., \& Williams, J. (2004). Confidence limits for the indirect effect: Distribution of the product and resampling methods. Multivariate Behavioral Research, 39(1), 99-128.

Maddalena, A., Richards, C. S., McGinniss, M. J., Brothman, A., Desnick, R. J., Grier, R. E., et al. (2001). Technical standards and guidelines for fragile $\mathrm{X}$ : The first of a series of disease-specific supplements to the Standards and Guidelines for Clinical Genetics Laboratories of the American College of Medical Genetics. Genetics in Medicine, 3(3), 200-205.

Mailick, M., Hong, J., Greenberg, J., Dawalt, L. S., Baker, M. W., \& Rathouz, P. J. (2017). FMR1 genotype interacts with parenting stress to shape health and functional abilities in older age. American Journal of Medical Genetics Part B: Neuropsychiatric Genetics, 174(4), 399-412. https://doi.org/10.1002/ajmg.b.32529.

Mailick, M. R., Hong, J., Rathouz, P., Baker, M. W., Greenberg, J. S., Smith, L., \& Maenner, M. (2014). Low-normal FMR1 CGG repeat length: Phenotypic associations. Frontiers in Genetics, 5, 309. https://doi.org/10.3389/fgene.2014.00309.

McEwen, B. S. (1998). Stress, adaptation, and disease: Allostasis and allostatic load. Annals of the New York Academy of Sciences, 840(1), 33-44. https://doi.org/10.1111/j.1749-6632.1998.tb095 46.x.

O'Brien, P., \& Oyebode, F. (2003). Psychotropic medication and the heart. Advances in Psychiatric Treatment, 9(6), 414-423. https:// doi.org/10.1192/apt.9.6.414.

Peprah, E. (2012). Fragile X syndrome: The FMR1 CGG repeat distribution among world populations. Annals of Human Genetics, 76(2), 178-191. https://doi.org/10.1111/j.1469-1809.2011.00694.x.

Piven, J., Palmer, P., Landa, R., Santangelo, S., Jacobi, D., \& Childress, D. (1997). Personality and language characteristics in parents from multiple-incidence autism families. American Journal of Medical Genetics Part B: Neuropsychiatric Genetics, 74(4), 398-411.

Porges, S. W. (1985). U.S. Patent No. 4520944. Washington, DC: U.S. Patent and Trademark Office.

Porges, S. W. (2001). The polyvagal theory: Phylogenetic substrates of a social nervous system. International Journal of Psychophysiology, 42(2), 123-146. https://doi.org/10.1016/S0167 -8760(01)00162-3.

Porges, S. W. (2003). The polyvagal theory: Phylogenetic contributions to social behavior. Physiology and Behavior, 79(3), 503-513. https ://doi.org/10.1016/S0031-9384(03)00156-2.

Porges, S. W. (2007). The polyvagal perspective. Biological Psychology, 74(2), 116-143. https://doi.org/10.1016/j.biops ycho.2006.06.009.

Porges, S. W., \& Bohrer, R. E. (1990). Analyses of periodic processes in psychophysiological research. In J. T. Cacioppo \& L. G. Tassinary (Eds.), Principles of Psychophysiology: Physical, Social, and Inferential Elements (pp. 708-753). New York: Cambridge University Press.

Porges, S. W., Macellaio, M., Stanfill, S. D., McCue, K., Lewis, G. F., Harden, E. R., et al. (2013). Respiratory sinus arrhythmia and auditory processing in autism: Modifiable deficits of an integrated social engagement system? International Journal of Psychophysiology, 88(3), 161-279. https://doi.org/10.1016/j.ijpsy cho.2012.11.009.

Prutting, C. A. (1982). Pragmatics as social competence. Journal of Speech Language and Hearing Disorders, 47(2), 123-134.

Quintana, D. S., Guastella, A. J., Outhred, T., Hickie, I. B., \& Kemp, A. H. (2012). Heart rate variability is associated with emotion recognition: Direct evidence for a relationship between the autonomic nervous system and social cognition. International Journal of Psychophysiology, 86(2), 168-172. https://doi.org/10.1016/j. ijpsycho.2012.08.012.

Reisinger, L. M., Cornish, K. M., \& Fombonne, É (2011). Diagnostic differentiation of autism spectrum disorders and pragmatic language impairment. Journal of Autism and Developmental Disorders, 41(12), 1694-1704.

Roberts, J. E., Tonnsen, B., Robinson, A., \& Shinkareva, S. V. (2012). Heart activity and autistic behavior in infants and toddlers with fragile X syndrome. American Journal on Intellectual and Developmental Disabilities, 117(2), 90-102. https://doi. org/10.1352/1944-7558-117.2.90.

Roberts, J. E., Tonnsen, B. L., Robinson, A. R., Tackett, B., \& Clark, C. (2011). Physiological mechanisms of fear and anxiety in young children with fragile X. In J.E. Roberts \& H.C. Hazlett (Co-Chairs), Biomarkers and behavioral indicators of anxiety and fear in young males with fragile $X$ syndrome. Symposium presented at the 44th Annual Gatlinburg Conference of Intellectual Disabilities. In. San Antonio, TX.

Schneider, A., Johnston, C., Tassone, F., Sansone, S., Hagerman, R., Ferrer, E., et al. (2016). Broad autism spectrum and obsessivecompulsive symptoms in adults with the fragile $\mathrm{X}$ premutation. The Clinical Neuropsychologist, 30(6), 929-943.

Seltzer, M. M., Baker, M. W., Hong, J., Maenner, M., Greenberg, J., \& Mandel, D. (2012). Prevalence of CGG expansions of the FMR1 gene in a US population-based sample. American Journal of Medical Genetics Part B: Neuropsychiatric Genetics, 159B(5), 589-597. https://doi.org/10.1002/ajmg.b.32065.

Shrout, P. E., \& Bolger, N. (2002). Mediation in experimental and nonexperimental studies: New procedures and recommendations. Psychological Methods, 7(4), 422-445.

SPSS, I. (2012). Statistics for windows, version 20.0. Armonk, NY: IBM Corp.

Sumner, J. A., McLaughlin, K. A., Walsh, K., Sheridan, M. A., \& Koenen, K. C. (2015). Caregiving and 5-HTTLPR genotype predict adolescent physiological stress reactivity: Confirmatory tests of gene $\times$ environment interactions. Child Development, 86(4), 985-994.

Swineford, L. B., Thurm, A., Baird, G., Wetherby, A. M., \& Swedo, S. (2014). Social (pragmatic) communication disorder: A research review of this new DSM-5 diagnostic category. Journal of Neurodevelopmental Disorders, 6(1), 41.

Tassone, F., De Rubeis, S., Carosi, C., La Fata, G., Serpa, G., Raske, C., et al. (2011). Differential usage of transcriptional start sites and polyadenylation sites in FMR1 premutation alleles. Nucleic Acids Research, 39(14), 6172-6185. https://doi.org/10.1093/nar/ gkr100.

Tassone, F., Pan, R., Amiri, K., Taylor, A. K., \& Hagerman, P. J. (2008). A rapid polymerase chain reaction-based screening method for identification of all expanded alleles of the fragile $\mathrm{X}$ (FMR1) gene in newborn and high-risk populations. Journal of Molecular Diagnostics, 10(1), 43-49.

Thayer, J. F., Ahs, F., Fredrikson, M., Sollers, J. J., \& Wager, T. D. (2012). A meta-analysis of heart rate variability and neuroimaging studies: Implications for heart rate variability as a marker of stress and health. Neuroscience and Biobehavioral Reviews, 36, 747-756. https://doi.org/10.1016/j.neubi orev.2011.11.009.

Valeri, L., \& VanderWeele, T. J. (2013). Mediation analysis allowing for exposure-mediator interactions and causal interpretation: Theoretical assumptions and implementation with SAS and SPSS macros. Psychological Methods, 18(2), 137.

Wang, J. Y., Hessl, D., Iwahashi, C., Cheung, K., Schneider, A., Hagerman, R. J., et al. (2013). Influence of the fragile X mental retardation (FMR1) gene on the brain and working memory in men with normal FMR1 alleles. Neuroimage, 65(Supplement C), 288-298. https://doi.org/10.1016/j.neuroimage.2012.09.075. 
Watson, L. R., Baranek, G. T., Roberts, J. E., David, F. J., \& Perryman, T. Y. (2010). Behavioral and physiological responses to child-directed speech as predictors of communication outcomes in children with autism spectrum disorders. Journal of Speech, Language, and Hearing Research, 53(4), 1052-1064. https://doi. org/10.1044/1092-4388(2009/09-0096).

Weghofer, A., Tea, M.-K., Barad, D. H., Kim, A., Singer, C. F., Wagner, K., \& Gleicher, N. (2012). BRCA1/2 mutations appear embryo-lethal unless rescued by low (CGG $\mathrm{n}<26)$ FMR1 subgenotypes: Explanation for the "BRCA paradox"? PLOS ONE, 7(9), e44753. https://doi.org/10.1371/journal.pone.0044753.

Wheeler, A., Raspa, M., Hagerman, R., Mailick, M., \& Riley, C. (2017). Implications of the FMR 1 premutation for children, adolescents, adults, and their families. Pediatrics, 139, S172S182. https://doi.org/10.1542/peds.2016-1159D.

Whitehouse, A., Watt, H., Line, E., \& Bishop, D. (2009). Adult psychosocial outcomes of children with specific language impairment, pragmatic language impairment and autism. International Journal of Language and Communication Disorders, 44(4), 511-528.

Yang, A. C., Chen, T. J., Tsai, S. J., Hong, C. J., Kuo, C. H., Yang, C. H., \& Kao, K. P. (2010). BDNF Val66Met polymorphism alters sympathovagal balance in healthy subjects. American Journal of Medical Genetics Part B: Neuropsychiatric Genetics, 153B(5), 1024-1030. https://doi.org/10.1002/ajmg.b.31069. doi. 